Editorial

\title{
Ancora Imparo: A New Beginning toward Learning
}

\author{
Harjinder Singh Bhatoe ${ }^{1}$ \\ ${ }^{1}$ Department of Neurosciences, Max Super Specialty Hospital, \\ New Delhi, India \\ Indian J Neurosurg 2015;4:1.
}

Neurosurgery in 2015 is evolving from a discipline of ablation to restoration, and in the spring of 2015, we move to metamorphose and reinvent ourselves so that we can process the deluge of information in this age of the Internet. It is but natural that there is a change in the journal, in the light of the sobering thought that the neurosurgical knowledge is doubling every 5 years, and it is estimated that only about 20 to $30 \%$ of us will have the ability to remain updated. ${ }^{1}$ Learning, relearning, and thus remaining updated (and by corollary, relevant) would mean the ability to fuse conventional teaching with practical surgical skills. It is highly important to foresee the increasing role of hospital and operating room teaching programs (often with live beaming), aided by conference workshops and didactic teaching, with, most importantly, the opportunity to do it yourself under a mentor, or independently. A young resident opting for neurosurgery embarks on a career of lifelong learning. We as neurosurgeons have a duty to attain and maintain a high degree of competence and proficiency in skills, and nowhere this is more apparent than in the field of neurovascular surgery. There will be a higher interaction of intellectual neurosurgery and psychomotor skills that have been perfected over decades. Simulations are likely to play an increasing role in practical training, and the march of technology with integration with molecular biology, genetics, and minimally invasive endeavors is going to throw up exciting possibilities around us in the times to come.

It is in this scenario, when knowledge is in a state of churning, that I take charge of the responsibilities of the Editor of the Indian Journal of Neurosurgery. It will be my endeavor and responsibility to get this journal on its feet, so that it begins to leave its footprints on the sands of time. My watchwords will be unbiased receptiveness to ideas and innovations, create and establish philosophies, and to create knowledge without the fear of failure. Toward fulfillment of these goals, I can certainly bank upon the unabashed support, unending energy, and single-minded passion from the editorial team, principally, Drs. Sumit Sinha and Vivek Tandon.

Senior neurosurgeons of the Neurological Surgeons' Society of India and others affiliated with growth and evolution of neurosurgery in India will remain as admired and respected source of motivation. I am positive that they will set the bar a few notches higher with their counsel and wisdom.

With the change of publisher, the journal now sports a new, contemporary look, complemented by the online version as well as a responsive article submission and handling system. Readers can look forward to a changed layout, better pagination, and improved reproduction of figures and tables.

\section{Reference}

1 Apuzzo MLJ, Elder JB, Liu CY. The metamorphosis of neurological surgery and the reinvention of the neurosurgeon. Neurosurgery 2009;64(5):788-794, discussion 794-795
Address for correspondence Harjinder Singh Bhatoe, MCh, Director Neurosciences, Max Super Specialty Hospital PPG, 108A IP Extension, New Delhi 110092, India (e-mail: hsbhatoe@gmail.com).
DOI http://dx.doi.org/ 10.1055/s-0035-1549132. ISSN 2277-954X.

\footnotetext{
(C) 2015 Neurological Surgeons' Society of India
}

License terms

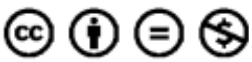

